\title{
Uso de recursos naturais por comunidades ribeirinhas amazônicas: bases para as políticas de concessões florestais
}

\section{Use of natural resources by Amazonian riverside communities: basis for forest concessions policies}

Luiz Cláudio Moreira Melo Júnior - Mestre em Planejamento do Desenvolvimento pelo Núcleo de Altos Estudos Amazônicos da Universidade Federal do Pará (NAEA/UFPA)/Brasil-Pará-Belém e Doutorando em Desenvolvimento Sustentável pelo Centro de Desenvolvimento Sustentável da Universidade de Brasília (CDS/UnB). E-mail: luiz.mmelo@hotmail.com

Manoel Malheiros Tourinho - PhD em Sociologia Rural pela Universidade de Wisconsin, Madison (EUA). E-mail: paratourinho@gmail.com

Doris Aleida Villamizar Sayago - Doutora em Sociologia pela Universidade de Brasília(UnB)/BrasilBrasília-Distrito Federal. E-mail: doris.sayago@gmail.com

Maria das Dores Correia Palha - Doutora em Ciências Biológicas pela Universidade Federal de Pernambuco (UFPE)/Brasil-Pernambuco-Recife. E-mail: faunaufra@gmail.com

\section{Resumo}

Este artigo trata das relações entre comunidades agrárias, recursos naturais, saberes e práticas locais no entorno de áreas destinadas a processos de concessão florestal, ao longo dos rios Mamuru e Arapiuns, estado do Pará. Para o levantamento de dados primários, foram aplicados questionários com a população dessas localidades. Construíramse mapas de uso dos recursos naturais para cada comunidade estudada, a partir dos usos múltiplos dos recursos lá encontrados. Como principal conclusão, o estudo aponta que um grande desafio é que as políticas de concessão florestal levem em consideração as áreas das comunidades como espaços de reprodução dos sistemas sociais comunitários e de uso coletivo dos recursos naturais. Caso contrário, esses espaços podem sofrer uma forte pressão antrópica em função das atraentes possibilidades de uso dos recursos naturais para fins comerciais e industriais.

\section{Palavras-chave}

Políticas Públicas. Concessão Florestal. Comunidades Ribeirinhas. Amazônia.

\section{Abstract}

This article deals with the relations between agrarian communities, natural resources, local knowledge and practices around the areas destined to forest concession processes along Mamuru and Arapiuns rivers, state of Pará. For primary data collection, questionnaires were filled with the population of these localities. Maps of natural resource use were constructed for each community studied, from the multiple uses of resources by communities. As a main conclusion the study indicates that a major challenge is that the policies of forest concession consider the areas of the communities as spaces for reproduction of the community social systems as well as collective use of natural resources. Otherwise, may suffer a strong anthropogenic pressure due to the attractive possibilities of use of natural resources for commercial and industrial purposes.

\section{Keywords}

Public Policies. Forest Concession. Riverine Communities. Amazon. 


\section{INTRODUÇÃO}

Este artigo trata das relações entre comunidades agrárias, recursos naturais, saberes e práticas locais ao longo dos rios Mamuru e Arapiuns, estado do Pará. $O$ conceito de saber local aqui empregado se refere ao conhecimento que as comunidades detêm sobre o uso e manejo dos recursos naturais, empregando técnicas e tecnologias, sejam elas "tradicionais" ou "modernas".

O objetivo do artigo é sistematizar e analisar os saberes e os padrões locais de uso dos recursos naturais por parte das comunidades ribeirinhas dos rios Mamuru e Arapiuns. Trata-se de uma região na qual o governo do estado do Pará, desde 2010, faz concessões de uma parte das florestas públicas para a iniciativa privada, como parte da política florestal brasileira (Lei 11.284, de 02.03.2006). O desafio que se coloca é o de apresentar reflexões com vistas à formulação de políticas públicas com respeito à governança de recursos florestais, sem que estas venham afetar de forma dramática as populações locais do Mamuru-Arapiuns.

A área estudada é constituída de vilas e povoados que se distribuem ao longo dos rios Mamuru e Arapiuns e às margens da estrada que, partindo de Itaituba, alcança as cabeceiras do rio Mamuru. Aproximadamente 80 comunidades abrigam cerca de 12.000 pessoas. Trata-se de uma área de baixa antropização, com ligeiras manchas antrópicas ao longo dos cursos dos rios e dos eixos de penetração terrestre das estradas de acesso, como a Translago e a Itaituba - alto rio Mamuru.

Entretanto, é uma área que, devido às possibilidades de uso produtivo dos recursos naturais (solos agrícolas, florestas e minérios), é passível de sofrer uma crescente pressão antrópica, atingindo diretamente as populações locais. Este cenário pode dificultar o livre acesso das comunidades aos recursos naturais e promover uma desarticulação social, com a consequente migração da população para os espaços urbanos dos municípios de Santarém, Juruti, Aveiro e Itaituba.

$\mathrm{O}$ artigo está estruturado em cinco seções, além desta introdução e das considerações finais. A primeira seção traz a abordagem dos referenciais teóricos para fundamentação quanto aos espaços de uso coletivo de recursos naturais e múltiplas formas de uso de recursos extraídos do próprio ambiente local. A segunda apresenta as ferramentas metodológicas utilizadas no trabalho e a zona de estudo. A terceira trata do uso de recursos naturais nas comunidades do Mamuru-Arapiuns. A quarta e a quinta abordam, respectivamente, a percepção dos membros das comunidades sobre as mudanças ambientais em curso e as concessões florestais que advirão. Isso é feito a partir da análise de dados primários e da delimitação das áreas das comunidades estudadas, considerando informações prestadas pelos moradores sobre os seus usos múltiplos dos recursos naturais.

Novos Cadernos NAEA • v. 16 n. $1 \bullet$ p. 79-100 • jun. 2013 


\section{REFERENCIAL TEÓRICO}

O território é importante para se estabelecer as características físicas e ambientais determinantes dos processos de relações entre a comunidade e os recursos naturais. Ele determina, ainda, o tipo de relações entre a comunidade e o ambiente externo, definindo o espaço de uso dos recursos naturais. Por sua vez, a presença dos recursos naturais e o uso ou a forma de apropriação definem a estrutura social, assim como a organização social da comunidade, resultando em processos sociais, como o conflito, a competição e a cooperação (TOURINHO, 2007).

Neste trabalho, conjugam-se os conceitos de território e comunidade, conforme definidos por Koenig (1988, p. 43), como "um grupo de pessoas que ocupam um território definido com o qual se identificam, e em que há um determinado grau de solidariedade". Nesse conceito, Tourinho (2007) destaca três elementos fundamentais da análise das relações entre a comunidade e o uso dos recursos naturais: os grupos sociais; o território definido, onde estão presentes os recursos naturais e a interação social, produto da estrutura e da organização da comunidade.

Por outro lado, o debate em torno da relação das sociedades com seus ambientes naturais é repleto de mitos. Um deles diz respeito à existência de um vínculo harmonioso entre sociedade e natureza nos tempos pré-industriais. Trata-se de uma afirmação duvidosa não apenas por sua generalidade, haja vista considerar como iguais todas as sociedades pré-industriais, além da visão romântica de sugerir que as ditas sociedades possuem um grau de consciência e atividade planificadas difícil de imaginar, mesmo no caso de grupos pequenos (FOLADORI; TAKS, 2004).

Todavia, criticar o pensamento ambiental romântico não significa ser indiferente às práticas tradicionais, frequentemente consideradas ineficientes pela ciência (FOLADORI; TAKS, 2004). Além do mais, a expressão "tradicional" é relativa, podendo conjugar o legado de crenças e técnicas geradas no passado com a utilização desse saber local no desenvolvimento das comunidades, sem deixar de lado as vantagens da realidade presente. Isto é, até mesmo a tradição pode se modernizar ou mesmo as antigas "modernidades" podem se tornar "tradicionais" quando subsumidas por novas modernidades (SAYAGO; BURSZTYN, 2006).

Ainda assim, e mesmo que seja uma categoria abrangente, as populações tradicionais são tidas como atores importantes na proteção do ambiente natural no qual estão inseridas (DIEGUES, 2001; CUNHA; ALMEIDA, 2009; PEREIRA; DIEGUES, 2010). A ideia é de que a diversidade cultural não pode 
estar divorciada da diversidade biológica (SHIVA, 2003; WALDMAN, 2006; TEISSERENC, 2010). Daí o interesse na manutenção dos estilos de vida que se mantiveram regrados pela tradição, como é o caso de ribeirinhos, seringueiros, castanheiros, indígenas, quilombolas e suas formas próprias de uso dos recursos naturais (WALDMAN, 2006; WITKOSKI, 2010). Dentre estas formas, destacamse os sistemas de uso coletivo, nos quais regras e normas existem com vistas a especificar aos grupos sociais os mecanismos de manejo, dentro do território da comunidade, definindo espaços de coleta, de caça e de cultivo (ALMEIDA, 1989; BARBOSA; MARIN, 2010).

No caso da Amazônia, Maués (2000) argumenta que, embora se valorize o desenvolvimento sustentável, desconhece-se que muito antes do atual movimento de defesa do meio ambiente e da ecologia, as populações nativas, como os índios e caboclos, já tinham uma grande preocupação com essa questão. Nesse sentido, várias crenças e mitos tradicionais amazônicos, como as ligadas a seres sobrenaturais, como o curupira e a mãe-dos-rios ou das matas, também constituem formas míticas de defesa do ambiente natural contra abusos e depredações. Daí a necessidade de incentivar o conhecimento da cultura das populações tradicionais amazônicas, inclusive as relações entre religiosidade e natureza, conforme abordagem de Palha e Tourinho (2009) para as populações ribeirinhas do estuário do rio Amazonas.

Argumenta-se que a natureza se apresenta para esses grupos como um lugar de permanente observação, experiência e reprodução de saberes (CASTRO, 2004). Uma das características das comunidades tradicionais é a produção de interpretações e análises oriundas de critérios e enfoques autóctones, diferenciando a sociedade do "ser" da sociedade do "ter" (SAYAGO; BURSZTYN, 2006). Ademais, a riqueza cultural e a consistência social das sociedades tradicionais residiriam na sua escala, no seu sistema de valores, na sua visão não mercantil do mundo (SAYAGO; BURSZTYN, 2006) e no uso de tecnologias simples, com baixo impacto ambiental (SCHUMACHER, 1979).

A adaptação das comunidades tradicionais a um meio ecológico de elevada complexidade é realizada graças aos saberes que elas acumulam sobre o território e às diferentes formas pelas quais o trabalho é realizado (CASTRO, 2004). Exemplo disso são as denominações "terras, florestas e águas de trabalho", que refletem múltiplas formas de uso dos recursos naturais (WITKOSKI, 2010; PEREIRA; WITKOSKI, 2012). Trata-se, antes de tudo, de uma lógica de produção que se orienta não por critérios de eficiência do capital, mas por critérios de eficiência reprodutiva, pois o que está em jogo é a reprodução da comunidade e das famílias enquanto unidades de produção. Explica-se, então,

Novos Cadernos NAEA • v. 16 n. 1 • p. 79-100 • jun. 2013 
a não separação entre as esferas da produção e do consumo, diferentemente do que ocorre em estruturas capitalistas (COSTA, 2005; 2012).

As atividades dessas populações são complexas, pois constituem múltiplas formas de relacionamento com os recursos que asseguram a reprodução do grupo e possibilitam a construção de uma cultura integrada à natureza e formas apropriadas de manejo (CASTRO, 2004). Por isso, Sayago et al. (2004), ao analisarem o padrão de ocupação do espaço geográfico amazônico em termos históricos, chegam a uma conclusão importante: as atividades tradicionais são mais duradouras (portanto, mais sustentáveis), enquanto que as modernidades são efêmeras.

No âmbito das políticas públicas, as comunidades tradicionais são tratadas formalmente. O Decreto Federal 6.040, de 07.02.2007, no seu Artigo 3, define povos e comunidades tradicionais como:

I - Povos e comunidades tradicionais: grupos culturalmente diferenciados e que se reconhecem como tais, que possuem formas próprias de organização social, que ocupam e usam territórios e recursos naturais como condição para sua reprodução cultural, social, religiosa, ancestral e econômica, utilizando conhecimentos, inovações e práticas gerados e transmitidos pela tradição.

Embora esta definição apresente aspectos importantes, como a noção de organização social, território e recursos naturais, o que se busca é a valorização de dimensões como a noção, a percepção e o uso do território. No caso das comunidades ribeirinhas do Mamuru-Arapiuns, o que se buscou neste artigo foi a identificação de mapas de uso dos recursos naturais pelas comunidades, como expressão das relações homem e natureza, no âmbito dos sistemas sociais comunitários, como o subsistema familiar ribeirinho.

\section{METODOLOGIA E ZONA DE ESTUDO}

A área estudada possui no seu limite ocidental o curso do rio Amazonas; e, no seu limite mais oriental, o médio e baixo curso do rio Tapajós, entre as cidades de Itaituba e Santarém. É caracterizada pela existência de diversas comunidades que vivem do extrativismo florestal, da pesca artesanal e da agricultura de base familiar. Tais comunidades se integram por meio dos rios e igarapés e se volvem de vários modos para uma relação de dependência para com cidades-sedes municipais, que atuam como centros comerciais e de serviços especializados. Dentre elas, a mais importante é Santarém, na confluência dos rios Tapajós e Amazonas (Figura1). 
Figura 1: Localização da área de estudo

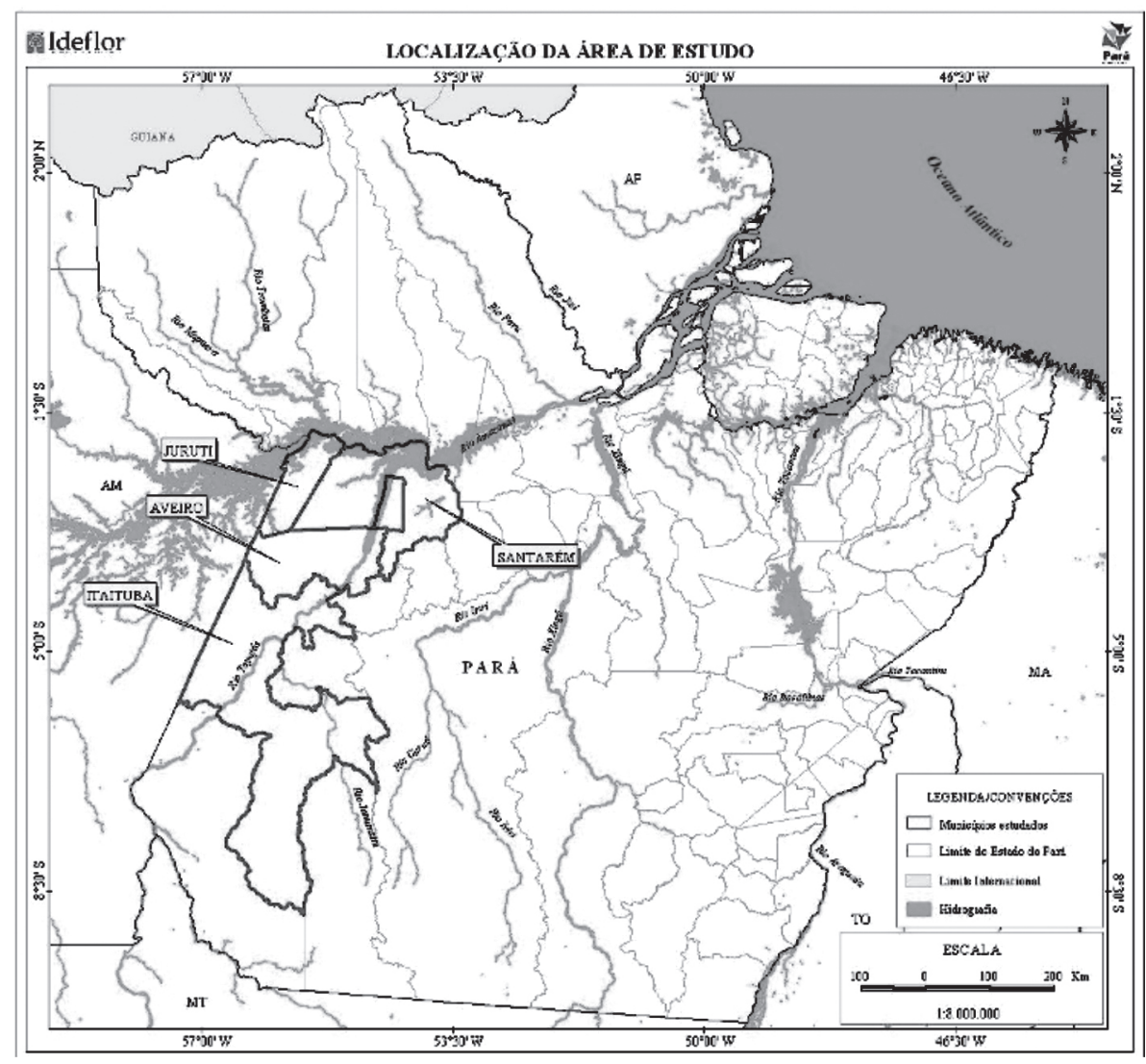

Fonte: Relatório IDEFLOR (2009)

Os questionários aplicados foram elaborados por uma equipe de professores e pesquisadores do Projeto Várzea e do Projeto Bio-fauna da Universidade Federal Rural da Amazônia (UFRA). Ambos os projetos são de natureza interdisciplinar, voltados para a investigação da articulação do ecossistema várzea nas suas dimensões ecológica, econômica e humana, visando contribuir para o conhecimento sistêmico, tanto de natureza biológica quanto sociológica.

Foram aplicados dois questionários temáticos: 1) comunidades e 2) uso de recursos florestais. Buscou-se entrevistar atores-chave, tais como líderes comunitários, professores, agentes de saúde, operadores de motosserras e caçadores, entre outros. Foram estudadas 20 comunidades, distribuídas nas seguintes regiões: 
Eixo 1 - Itaituba-Alto Mamuru: 4 comunidades;

Eixo 2 - Baixo e Médio Mamuru: 8 comunidades;

Eixo 3 - Rio Arapiuns - Translago: 8 comunidades.

A amostragem abrangeu $20 \%$ das famílias de cada comunidade selecionada. Entrevistaram-se 365 moradores. A pesquisa ocorreu no período de 24.11.2008 a 05.12.2008. Todas as comunidades foram georrenferenciadas. A partir de informações fornecidas pelos atores-chave e outros moradores, quanto às direções e distâncias seguidas e percorridas para coleta dos produtos da terra, dos rios, dos igarapés e da floresta (roça, pesca, caça e espécies florestais madeireiras e não madeireiras), estabeleceu-se uma superfície aproximada das mesmas, com forte validação cultural, uma vez que foram determinadas a partir do saber local e do uso de recursos naturais pela comunidade.

O conteúdo dos questionários, por sua vez, abrangia questões ligadas à relação entre a comunidade e os recursos naturais, como: a) o material usado na construção das residências; b) o uso comunitário de espécies florestais madeireiras e não madeireiras; c) a percepção dos entrevistados sobre possíveis mudanças ambientais e de que forma essas mudanças afetam a vida e o trabalho na comunidade; e, d) o entendimento dos entrevistados sobre as concessões florestais.

\section{USO DOS RECURSOS NATURAIS PELAS COMUNIDADES RIBEIRINHAS DO MAMURU-ARAPIUNS}

No estudo das relações entre comunidade e recursos naturais no MamuruArapiuns, consideram-se como ponto de partida as abordagens dos estudos de comunidades ribeirinhas amazônicas (WAGLEY, 1957; MORAES, 1987; TOCANTINS, 1988). Nestes, as comunidades não são tomadas como unidades isoladas, no que se refere à paisagem geográfica ou social das mesmas, mas consideram-se todas as relações possíveis, empíricas e verificáveis, inclusive aquelas derivadas do próprio processo de ocupação histórica dos territórios.

As comunidades do Mamuru-Arapiuns, por exemplo, são recentes. As mais antigas estão localizadas no rio Arapiuns: Cachoeira do Aruã que foi fundada no início do século passado (1901) e Monte Sião e Curi que datam dos anos de 1950 (1953 e 1955). As comunidades do eixo Itaituba são ainda mais recentes: uma delas - Monte Verde - fundada na década de 1990, e duas outras são do século atual (anos de 2000 e 2004). Para as comunidades ribeirinhas do rio Mamuru, as fundações são dos anos 1960, 1970 e 1990. Apenas uma foi fundada no atual 
século, em 2000. Nas comunidades do Mamuru, as origens estão mais ligadas à exploração florestal, e as toponímias locais revelam essa identidade: Samaumeira, Guaranazal, Jarazeiro, Amiri etc.

Cerca de 3.070 pessoas vivem nas 20 comunidades estudadas. Essa população tem os seus "polos urbanos", onde se busca serviços e equipamentos urbanos: as comunidades do Arapiuns são todas orientadas para Santarém; apenas o Novo Paraíso se dirige para o urbano de Juruti; as que formam o eixo Itaituba buscam na cidade de Itaituba os serviços que precisam e as do Mamuru são todas orientadas para Parintins, no estado do Amazonas, embora pertencentes, do ponto de vista político e geográfico, ao estado do Pará.

Sobre as condições de acesso, 75\% das comunidades declararam o acesso pelo rio. Na região do Mamuru, o rio é a única via de acesso. No Arapiuns, 75\% das comunidades são acessadas pelo rio. Apenas as do eixo Itaituba têm como acesso a via terrestre, em sua maioria (75\%). Se considerarmos os rios como corredores naturais de conexão social (TOCANTINS, 1988), significa que os mesmos cumprem uma função de ligar os sistemas sociais comunitários com outras comunidades.

No caso das relações entre as comunidades e o uso de recursos naturais, um primeiro aspecto a ser destacado é o uso do barro, da madeira e da palha na construção das casas e outros abrigos como indicador da humanização da paisagem, do uso dos recursos proporcionados pela diversidade da mata e do mais amplo controle do processo produtivo e das técnicas de construção, numa alusão exemplar de relação sustentável entre homem e natureza. O material usado nas construções (barro, telhas, tábuas e palhas), assim como as técnicas de edificações, todas de amplo conhecimento das populações locais, conferem àquelas o total domínio do processo produtivo, essencialidade à condição de processo sustentável (FOSTER, 2005).

Além de refletir disponibilidade e uso de recursos naturais, entende-se que os materiais empregados nas construções são também manifestações culturais, pois refletem adaptações dos humanos ao meio ambiente (HAWLEY, 1986), como ilustra a Figura 2, que apresenta uma casa com telhado e paredes de palha na comunidade de Sumaúma, na região do rio Mamuru. 
Figura 2: Casa com telhado e paredes de palha, comunidade Sumaúma, região do rio Mamuru

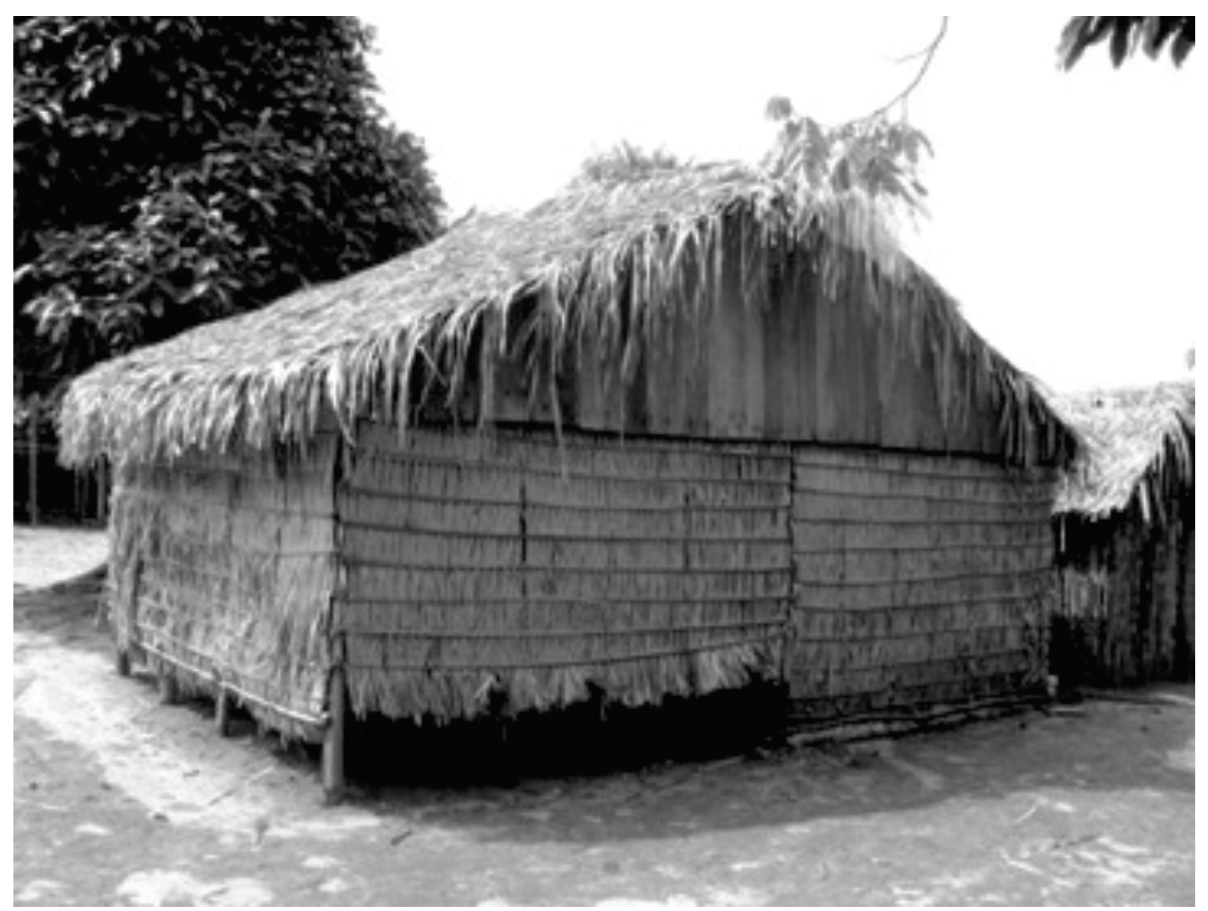

Fonte: Relatório IDEFLOR (2009)

Nos dados da Tabela 1, percebe-se uma forte relação entre os materiais usados nas construções e a natureza. O barro, a madeira e a palha foram os materiais mais frequentemente observados nas construções, porém eles aparecem de forma diferenciada segundo as comunidades estudadas. Em sua maioria, as paredes das residências ainda são erguidas com uso de madeira (68,9\%); a palha aparece em seguida, com 18,5\% de uso. Logo, esses recursos naturais locais são usados em $87,4 \%$ das moradias. Esses dois materiais são largamente empregados nas comunidades ribeirinhas do Mamuru e do Arapiuns (97,5\% e $90,2 \%$, respectivamente). 
Tabela 1: Material de construção usado nas residências da área de estudo

\begin{tabular}{l|c|c|c|c}
\hline \multicolumn{1}{c|}{ Material de construção } & Arapiuns & Itaituba & Mamuru & Total \\
\hline \multicolumn{5}{|c|}{ Paredes (\%) } \\
\hline Alvenaria & 1 & - & - & 0,4 \\
\hline Barro & - & 16,6 & - & 2,6 \\
\hline Madeira & 58,7 & 46,6 & 87,5 & 68,9 \\
\hline Mista & 8,7 & 30 & 2,5 & 9,4 \\
\hline Palha & 31,5 & 6,6 & 10 & 18,5 \\
\hline \multicolumn{5}{|c|}{ Cobertura (\%) } \\
\hline Amianto (tipo Brasilit) & 27,1 & 25 & 30 & 28 \\
\hline Cavaco & - & 41,6 & 1,2 & 6,7 \\
\hline Laje & - & - & - & - \\
\hline Palha & 71,1 & 33,3 & 61,2 & 60,2 \\
\hline Telha de barro & 1,7 & - & 7,5 & 3,9 \\
\hline \multicolumn{7}{|c|}{ Piso $(\%)$} & - & 0,2 \\
\hline Cerâmica & 0,5 & - & 6,2 & 10 \\
\hline Cimento & 16,8 & 5 & 23,1 & 52,5 \\
\hline Madeira & 16,5 & - & \\
\hline Terra batida & 66,1 & 95 & & \\
\hline
\end{tabular}

Fonte: Relatório IDEFLOR (2009)

No Mamuru, onde o uso da floresta parece ser mais presente na vida comunitária, é bem maior o emprego da madeira $(87,5 \%)$ e menor o uso da palha $(10 \%)$. Existem comunidades no Mamuru nas quais $100 \%$ das paredes são edificadas com madeira, como ocorre em Jaratuba, Nossa Senhora de Lourdes e Sabina. Nas comunidades do eixo Itaituba, as formas mistas $(30 \%)$ e o emprego do barro (16,6\%) parecem substituir a madeira (46,6\%). Já no Arapiuns, em algumas comunidades, o uso da madeira predomina em $90 \%$ das residências, como é o caso de Cachoeira do Aruã; e em outras, como é o caso de Novo Paraíso, esse uso baixa a 15\% apenas. Modernidade e/ou falta do recurso?

O material usado para cobertura das residências segue a mesma tendência das paredes: telhas de barro, cavaco ${ }^{1}$ e palha alcançam a expressão de $70,8 \%$ de uso. A palha, que perfaz um total de uso da ordem de $60,2 \%$, tem a sua maior expressão nas comunidades dos rios: mais de $60 \%$ das residências. $O$ cavaco é usado em apenas $6,75 \%$ do total e alcança no eixo Itaituba a sua maior participação: 41,6\% das residências recorrem a esse tipo de produto da floresta, enquanto que no Mamuru ocorre em apenas 1,3\% e nas do Arapiuns não se observou o emprego deste tipo de material. As telhas de barro são empregadas em apenas 3,8\% das casas. No Arapiuns aparecem em quase 2\% das coberturas,

$1 \quad$ Fragmento fino e longo de madeira.

Novos Cadernos NAEA • v. 16 n. $1 \bullet$ p. 79-100 • jun. 2013 
enquanto no Mamuru aparecem em 7,5\%. Merece nota o emprego de telhas de cimento-amianto, que são utilizadas em $28 \%$ das moradias, com percentuais elevados em todas as comunidades. As ribeirinhas apresentam usos mais elevados (no Mamuru alcança 30\%) que as continentais do eixo Itaituba. Nenhuma cobertura com laje de cimento-concreto foi observada.

Os pisos das residências são feitos, em sua maioria, de terra batida $(52,5 \%)$ e madeira (36,8\%). As comunidades se diferenciam também quanto aos materiais que empregam: no Arapiuns existem mais pisos de terra batida (66,1\%) que no Mamuru (23\%). Entretanto, ambas as regiões são superadas pelas proporções encontradas no eixo Itaituba (95\%). Pisos de madeira existem em 70\% das residências do Mamuru e em 17\% do Arapiuns. Não foi constatado o emprego de madeira nos pisos das moradias do Itaituba. O cimento e a cerâmica aparecem apenas em pequenas proporções. O cimento chega a $10 \%$ das residências, enquanto a cerâmica não alcança 1\%. Entretanto, merece ser mencionado que o cimento tem emprego destacado nas comunidades do Arapiuns, onde a maior proporção de residências com piso de cimento (40\%) situa-se no Curi.

Em síntese, os dados dos materiais empregados na construção das residências das comunidades revelam uma estreita relação com recursos extraídos do próprio ambiente local, com destaque para a madeira e a palha, utilizados em mais de $87 \%$ das residências das comunidades estudadas.

Outro aspecto a ser considerado é o uso de cipós, sementes, frutos, animais de caça, além de árvores madeiráveis. Quanto aos múltiplos produtos da mata, foram registradas 96 espécies utilizadas. $O$ número de espécies usadas em cada área de estudo foi 85 (Mamuru), 17 (Itaituba) e 44 (Arapiuns). As espécies mais citadas nas três áreas de estudo foram açaí (Euterpe oleracea Mart.), amapá (Brosimum parinarioides Ducke), andiroba (Carapa guianensis Aubl.), angelim (Hymenolobium sp.), angelim-pedra (Hymenolobium petraeum Ducke), cedro (Cedrela odorata Ruiz \& Pav.), cedrorana (Cedrelinga catanaeformis Ducke), cipó-titica (Heteropis flexuosa (H.B.K.) G.S. Bunting), copaíba (Copaifera reticulata Ducke), cumaru (Dipteryx odorata (Aubl) Willd.), itaúba (Mequilaurus itauba Taubert ex Mez.), maçaranduba (Manilkara buberi (Ducke) Chevalier), marupá (Simaruba amara Aubl.), muiracatiara (Astroniumlecointei Ducke) e pau d'arco (Tabebuia serratifolia (Vahl) G. Nicholson). 15 espécies $(15,6 \%)$ foram comuns às três áreas de pesquisa. As espécies mais citadas na região do Arapiuns foram cupiúba (Goupia glabra (Gmel.) Aublet) e itaúba (Mequilaurus itauba Taubert ex Mez.). Na região do Mamurú, destacaram-se: itaúba (Mezilaurus itauba Taubert ex Mez.) e muiracatiara (Astroniumle-cointei Ducke). E na região de Itaituba, o pau d'arco (Tabebuia serratifolia (Vahl) G. Nicholson). 
Quanto ao tipo de uso e finalidade, 27 espécies na região do Arapiuns foram registradas como sendo de uso múltiplo. O uso mais frequente foi o de cipós, com destaque ao cipó-ambé (Philodendron solimoensis A.C. Smith) e cipótitica (Heteropis flexuosa (H.B.K.) G. S. Bunting), seguidos do uso de casca de barbatimão (Stryphnodrendron brabatimam Mart.). Essas três espécies são usadas na terapia e medicina caseira. Destaca-se, ainda, a produção de palhas de tucumãzeiro (Astrocaryum vulgare Mart.), usadas na cobertura de casas. Na média, 52,8\% das espécies possuem a finalidade para venda e 47,2\% para consumo. No geral, 75\% das espécies servem para consumo e venda. São usadas apenas para consumo familiar 23 espécies florestais, a saber: abuta (Abuta grandifolia (Mart) Sandwith), açaí (Euterpe oleracea Mart. - fruto e palmito: alimentação), anani (Symphonia globulifera L.), andiroba (Carapa guianensis Aubl. - fruto e óleo: medicinal), arumã (Thalia geniculata L.), bacaba (Oenocarpus bacaba Mart. - fruto: alimentação), breu (Protium heptaphyllum (Aubl.) March. - exudado: medicinal), buriti (Mauritia flexuosa L. - fruto: alimentação), carapanaúba (Aspidosperma carapanauba Pichon.), castanha-do-Pará (Bertholletia excelsa H. B. K. - castanha: alimentação), comandá (sp-1), copaíba (Copaifera reticulata Ducke - óleo: medicinal), jucá (Peltogyne paniculata Benth. - fruto: medicinal), mururé (Brosimum obovata Ducke), muúba (Bellucia imperialis Sad. et. C. ex. Cogn), patauá (Jesseniabatana (Mart.) Burret fruto: alimentação), piquiá (Caryocarvillosum (Aubl.) Pers.), preciosa (Anibacanellila Mez.), sucuba (Himatanthus sucuuba (Sppruce) Woodson), tachi (Tachigalia sp.), ucuúba (Virola michelii Heckel), uxi-liso (Endopleura uchi (Hub) Cuart.) e verônica (Dalbergia monetária L. F. - casca: medicinal).

Com a finalidade de determinar o tamanho do território de uso coletivo pelos moradores ribeirinhos das comunidades do Mamuru-Arapiuns, perguntouse a informantes-chave, como coletores, agricultores, caçadores, pescadores e donas de casas, as direções geográficas e as respectivas distâncias percorridas para a busca dos produtos madeiráveis e não madeiráveis; para o abastecimento de água para uso doméstico; para os roçados de produção agrícola; para os rios e igarapés de uso comunitário para pesca e transporte; além dos locais e rumos de caça, entre outros produtos e atividades.

As diferentes formas de uso da terra indicadas pelas comunidades, com suas respectivas direções espaciais e as distâncias que os comunitários percorrem para obter esses recursos foram georreferenciadas, processadas pelas equipes de campo e de laboratório da UFRA e do IDEFLOR e considerados na elaboração 
de mapas de uso dos recursos naturais pelas comunidades estudadas. Trata-se de uma área de uso comum em termos de caça, pesca, roçado e uso da floresta por parte das comunidades ribeirinhas dos rios Mamuru e Arapiuns.

A média das áreas das comunidades estudadas foi de 5.744,7 ha. Os formatos das áreas, por sua vez, foram os mais diversos possíveis, assim como as áreas destinadas à agricultura, ao uso da fauna e ao uso de recursos florestais madeireiros e não madeireiros, conforme se observa nas Figuras 3 e 4, apenas como ilustração do resultado da metodologia desenvolvida pelos pesquisadores dos Projetos Várzea e Bio-Fauna para a pesquisa referencial deste estudo.

Os Figuras 3 e 4 representam duas das comunidades estudadas: uma localizada no rio Arapiuns (Cachoeira do Aruã) e outra no rio Mamuru (Guaranatuba). Conforme se observa no Figura 3, a área total de uso da comunidade Cachoeira do Aruã foi de 10.654,8 ha, dos quais 1.590,5 ha são destinados para agricultura; 6.358 ha para uso da fauna e 2.477,7 ha para utilização de recursos florestais madeireiros e não madeireiros. Já o espaço de uso da comunidade de Guaranatuba (Figura 4) correspondeu a uma área de 9.659,6 ha, divididos da seguinte forma: 17 ha destinados para agricultura; 5.479,9 ha para uso da fauna; 872,5 ha para recursos florestais não madeireiros e 2.038,5 ha para recursos florestais madeireiros.

Vale salientar a diversidade observada entre as comunidades estudadas em termos do tamanho das áreas usadas para cada tipo de atividade. As áreas destinadas para agricultura, por exemplo, variaram entre 4,2 ha, nas comunidades Forca (rio Arapiuns) e Marinzal (rio Mamuru), até 1.770,4 ha na comunidade Curi (rio Arapiuns). As áreas destinadas para fauna variaram entre 73,5 ha, na Vila Sabina, a 7.319,2ha, na comunidade Mocambo, ambas no rio Mamuru.

As áreas de uso de recursos florestais madeireiros e não madeireiros, por sua vez, coincidem em 8 comunidades: Cachoeira do Aruã (2.477,7 ha), Camará (1.381, 9 ha), Curi (1.840,4 ha), Monte Sião (1.060,5 ha), Novo Horizonte (994,7 ha), Novo Paraíso (1.802,6 ha), São José (1.963,2 ha) e São Luiz (1.480,8 ha). Nas demais comunidades há diferenças entre essas áreas. A menor área destinada à exploração de recursos florestais não madeireiros foi encontrada na comunidade Vila Sabina (120,6 ha) e, a maior, na comunidade Monte Carmelo (7.091,1 ha). As áreas destinadas para recursos florestais madeireiros atingiram a maior expressão na Cachoeira do Aruã (6.358 ha) e, a menor, na comunidade Forca (203,3 ha). 
Figura 3: Área da comunidade Cachoeira do Aruã - Arapiuns

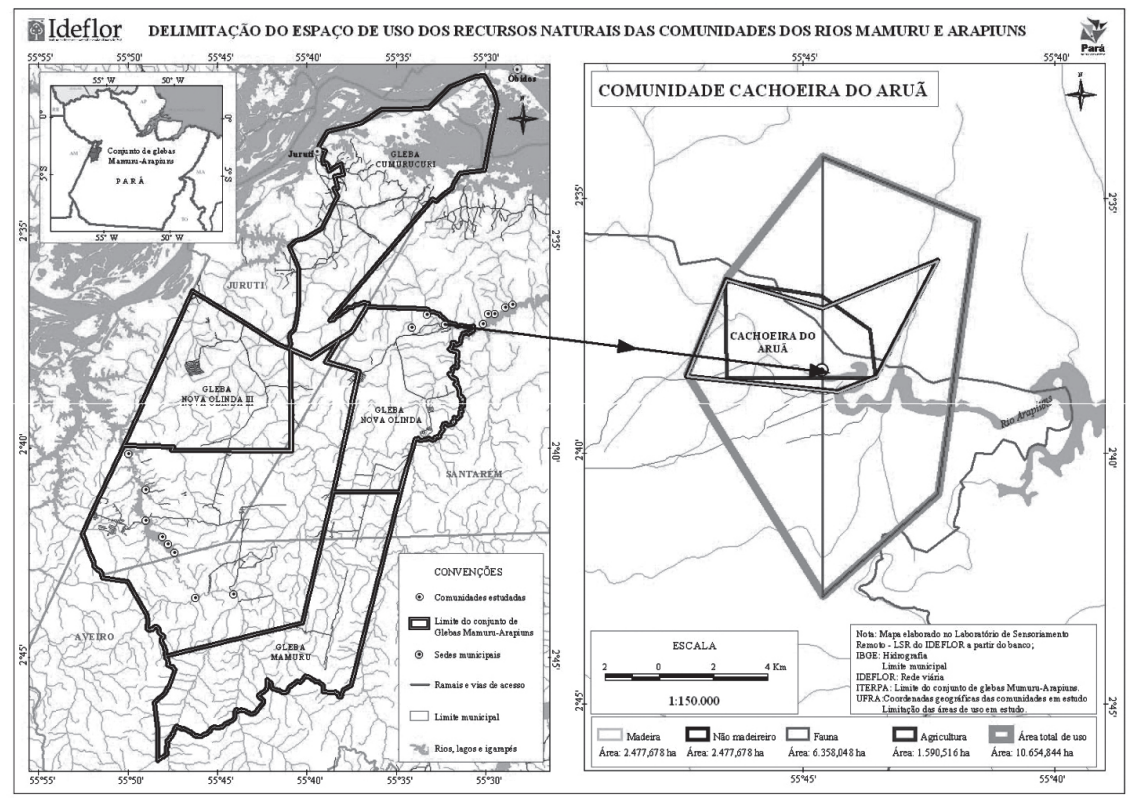

Fonte: Relatório IDEFLOR (2009)

Figura 4: Área da comunidade Guaranatuba - Mamuru

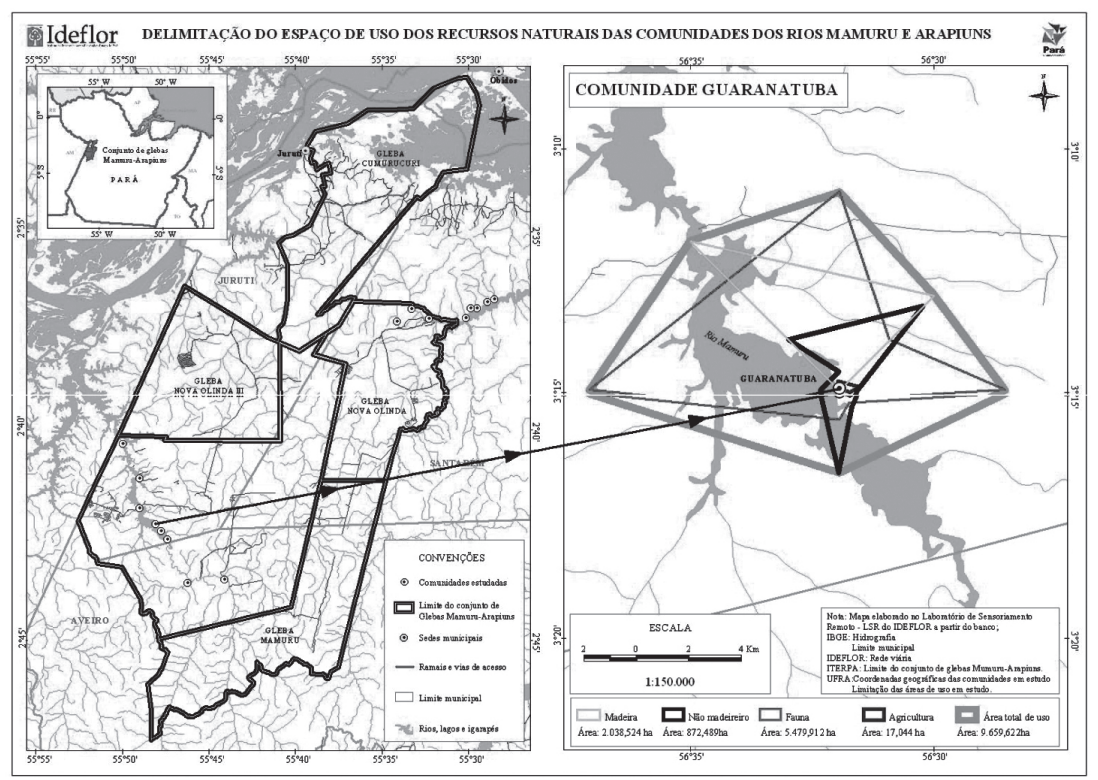

Fonte: Relatório IDEFLOR (2009) 


\section{PERCEPÇÃO DOS COMUNITÁRIOS SOBRE MUDANÇAS AMBIENTAIS}

Pode-se observar que em determinados locais a extração e o uso de recursos naturais não são comuns, como sugere a pesquisa em algumas comunidades do eixo Arapiuns e do eixo Itaituba, quanto ao emprego de material primário nas construções, por exemplo. Cabe então indagar: seriam efeitos da modernidade ou refletem a falta dos recursos usados nas edificações? Ou, ainda, seriam mudanças ambientais provocando alterações nos ciclos dos produtos florestais e na sua disponibilidade? Daí a importância de se conhecer a percepção dos moradores das comunidades sobre possíveis mudanças ambientais e de que forma essas mudanças estariam afetando ou não a disponibilidade de recursos naturais e, por conseguinte, os padrões locais de uso de recursos naturais.

Tal percepção, ao tempo em que é expressão do saber local, aponta para a importância de abordagens integradas no trato da questão ambiental, dada sua relação com aspectos como a saúde e o impacto dessas mudanças nos sistemas sociais comunitários. A Tabela 2 apresenta a percepção dos entrevistados sobre possíveis mudanças ambientais e seus efeitos na vida comunitária, a partir da indicação dos problemas que teriam origem na questão ambiental.

Tabela 2: Percepção dos impactos ambientais e seus efeitos nas comunidades das áreas de estudo

\begin{tabular}{l|c|c|c|c|c|c|c|c}
\hline \multirow{2}{*}{ Questão } & \multicolumn{2}{|c|}{$\begin{array}{c}\text { Arapiuns } \\
(\%)\end{array}$} & \multicolumn{2}{c|}{ Itaituba (\%) } & \multicolumn{2}{c|}{$\begin{array}{c}\text { Mamuru } \\
(\%)\end{array}$} & \multicolumn{2}{c}{ Total (\%) } \\
\cline { 2 - 10 } & Sim & Não & Sim & Não & Sim & Não & Sim & Não \\
\hline Ambiente está mudando? & 87,5 & 12,5 & 100 & - & 100 & - & 95 & 5 \\
\hline $\begin{array}{l}\text { Essa mudança afeta a vida } \\
\text { e trabalho na comunidade? }\end{array}$ & 25 & 75 & 100 & - & 100 & - & 70 & 30 \\
\hline
\end{tabular}

\begin{tabular}{l|c|c|c|c|c|c|c|c}
\hline \multicolumn{1}{c}{ Problemas com origem na questão ambiental } \\
\hline Doenças contagiosas & - & 100 & - & 100 & - & 100 & - & 100 \\
\hline Doenças infecciosas & - & 100 & - & 100 & 12,5 & 87,5 & 5 & 95 \\
\hline Doenças respiratórias & 100 & - & 25 & 75 & - & 100 & 45 & 55 \\
\hline Doenças de pele & 12,5 & 87,5 & 25 & 75 & 75 & 25 & 40 & 60 \\
\hline Água poluída & - & 100 & - & 100 & 12,5 & 87,5 & 5 & 95 \\
\hline Água suja & 37,5 & 62,5 & 75 & 25 & 62,5 & 37,5 & 55 & 45 \\
\hline Nascente secando & 12,5 & 87,5 & - & 100 & - & 100 & 5 & 95 \\
\hline Falta de chuvas & - & 100 & - & 100 & - & 100 & - & 100 \\
\hline Escassez de pesca & 87,5 & 12,5 & 25 & 75 & 62,5 & 37,5 & 65 & 35 \\
\hline Escassez de caça & 75 & 25 & 75 & 25 & 100 & - & 85 & 15 \\
\hline
\end{tabular}

Fonte: Relatório IDEFLOR (2009) 
Para 95\% dos entrevistados o ambiente está mudando e 70\% deles consideram que essas mudanças afetam a vida e o trabalho na comunidade. Os efeitos disso sobre os sistemas sociais comunitários e o uso de recursos naturais, por sua vez, parecem ser mais sentidos na escassez de caça (85\%) e na escassez de pesca $(65 \%)$. No que diz respeito aos problemas relacionados à saúde que teriam origem na questão ambiental, as doenças respiratórias (45\%) e as doenças de pele $(40 \%)$ foram as mais citadas pelos comunitários. E quanto à água? Merece nota o fato de que "nascente secando" e "falta de chuvas" não foram indicados como problemas pelos entrevistados. Também não parece existir percepção quanto a agentes químicos poluindo as águas nas comunidades estudadas: apenas uma, no Mamuru, apontou este fato. Mas os igarapés e os rios como fonte de suprimento são vistos como "sujos" por 55\% do total de entrevistados.

Indagou-se também o que os moradores sabem sobre possíveis atividades causadoras de degradação ambiental nos arredores das comunidades. A existência de áreas já queimadas (95\%) e áreas já desmatadas $(90 \%)$ foram as mais citadas pelos entrevistados. A ocorrência de desmatamentos foi a resposta de $45 \%$ dos entrevistados, sendo maior a frequência entre as comunidades dos eixos Itaituba e Mamuru. A existência de clareiras na mata foi citada por 35\% dos comunitários. Com relação a evidências naturais que podem ser atribuídas às alterações ambientais, como ocorrência de enchentes e mortandade de animais, algumas comunidades admitem a ocorrência desses indicadores. As enchentes foram citadas por $25 \%$ do total e a mortandade de animais, em decorrência de alterações ambientais, foi citada por $10 \%$ dos entrevistados. Presença de madeireiras (25\%), desmatamento em mata ciliar (25\%), campo de pouso (15\%), presença de mineradora na área $(5 \%)$ e grilagem de terra $(5 \%)$ também foram aspectos lembrados pelos entrevistados.

Identificada a percepção dos comunitários sobre mudanças ambientais e atividades causadoras de perturbação ambiental no entorno das comunidades, uma questão relevante é identificar a percepção dos moradores das comunidades ribeirinhas sobre as outorgas florestais. Trata-se de programa instituído, no ano de 2010, pelo governo do estado do Pará, cuja execução propõe a preservação das comunidades locais contra qualquer incursão dos grupos outorgados em busca de espécies de alto valor comercial existente apenas no entorno dessas comunidades. Perguntou-se então: o que os comunitários entendem sobre as concessões florestais? $\mathrm{Na}$ visão deles, é a concessão florestal a melhor alternativa de desenvolvimento sustentável para a região? 


\section{PERCEPÇÃO DOS COMUNITÁRIOS SOBRE AS CONCESSÕES FLORESTAIS}

Tendo em vista os usos múltiplos dos recursos naturais por parte das comunidades estudadas e a política do governo do estado do Pará de ceder uma parte das florestas públicas para a iniciativa privada, como parte da política florestal brasileira (Lei 11.284, de 02.03.2006), uma questão relevante é identificar o que pensam os comunitários sobre as concessões florestais. Constatou-se que a maioria dos entrevistados nas regiões do Arapiuns (81,8\%) e do Mamuru (98,2\%) não tinham a menor ideia do que seria uma concessão florestal, enquanto que $44,4 \%$ dos entrevistados na região de Itaituba declararam que tinham uma noção do que ela significava (Tabela 3).

Contudo, mesmo após a explicação dada pelos pesquisadores, a opinião dos moradores das comunidades, das três regiões estudadas, mostrou que 36,4\% dos entrevistados acham que a concessão florestal traria problemas fundiários e seria prejudicial para as comunidades. $27,3 \%$ temem que haja perda da biodiversidade e, apenas $9,1 \%$ acreditam que não haveria prejuízo para as comunidades. Outros $27,3 \%$ acham que a concessão iria gerar emprego e traria desenvolvimento à região. Ainda assim, observou-se que existem opiniões contraditórias nas comunidades estudadas.

Tabela 3: Opinião dos comunitários sobre as concessões florestais nas áreas de estudo

\begin{tabular}{|c|c|c|c|}
\hline \multirow{2}{*}{ Região } & \multicolumn{2}{|c|}{ Conhece $(\%)$} & \multirow{2}{*}{ Opinião } \\
\hline & Não & $\mathrm{Sim}$ & \\
\hline Arapiuns & 81,8 & 18,2 & $\begin{array}{l}\text { - Prejudicial para a comunidade } \\
\text { - Teme problemas fundiários } \\
\text { - Teme perda da biodiversidade }\end{array}$ \\
\hline Itaituba & 55,6 & 44,4 & $\begin{array}{l}\text { - Geração de emprego e renda } \\
\text { - Prejudicial para a comunidade } \\
\text { - Teme problemas fundiários } \\
\text { - Teme perda da biodiversidade }\end{array}$ \\
\hline Mamurú & 98,2 & 1,8 & $\begin{array}{l}\text { - Teme perda de biodiversidade } \\
\text { - Desenvolvimento para a região } \\
\text { - Geração de emprego e renda } \\
\text { - Não há prejuízo à comunidade }\end{array}$ \\
\hline Média & 89,5 & 10,5 & \\
\hline
\end{tabular}

Fonte: Relatório IDEFLOR (2009) 
Quando a análise é desagregada por região, 100\% dos entrevistados na região do Arapiuns e 75\% no Itaituba temem a efetivação da concessão florestal. $\mathrm{Na}$ região do Mamuru, 50\% dos entrevistados acham que ela seria positiva. No geral, 63,7\% dos entrevistados não veem a concessão florestal como a melhor alternativa de desenvolvimento sustentável para a região.

\section{CONSIDERAÇÕES FINAIS}

Embora a definição de comunidades tradicionais, formalizada pelo Decreto 6.040, de 07.02.2007, destaque elementos importantes como a função do território, dos recursos naturais, dos grupos e da organização social, a delimitação das áreas das comunidades ribeirinhas dos rios Mamuru e Arapiuns teve como objetivo a valorização de aspectos como a noção, a percepção e o uso do território por parte das comunidades. Trata-se de uma área de uso comum em termos de caça, pesca, roçado e uso da floresta, tendo em vista a função do território como espaço que garante a determinado grupo direitos estáveis de acesso, uso e controle dos recursos naturais, assim como sua disponibilidade ao longo do tempo (CASTRO, 2004).

No caso das comunidades ribeirinhas do Mamuru-Arapiuns, é a natureza do recurso, tanto a qualidade como a quantidade, que define os padrões de uso da terra e as formas de interação social. Daí a importância da ação do poder público na geração de políticas voltadas à preservação e conservação de um território comunal, com a garantia plena de que essas populações não serão desalojadas desse seu meio natural no qual operam ao seu modo cultural de vida o acesso, a gestão, o manejo comunitário dos recursos e, por fim, a sua reprodução social.

Um grande desafio é que as políticas públicas estaduais de concessão florestal considerem as áreas das comunidades como espaços de reprodução dos sistemas sociais comunitários e de uso dos recursos naturais. Caso contrário, pode sofrer uma forte pressão antrópica, atingindo diretamente as populações locais, em função das atraentes possibilidades de uso dos recursos naturais para fins comerciais e industriais (solos agrícolas, florestas e minérios). Tal cenário pode dificultar o livre acesso das comunidades aos recursos naturais, podendo provocar uma ampla desarticulação social e a consequente migração da população para os espaços urbanos dos municípios de Santarém, Juruti, Aveiro e Itaituba.

Entende-se que qualquer estratégia de desenvolvimento com esperança de sustentabilidade na Amazônia deve levar em consideração as múltiplas formas de uso e manejo dos recursos naturais por parte das populações locais, representadas, no caso em tela, pelas comunidades ribeirinhas do Mamuru-Arapiuns. Infere-se

Novos Cadernos NAEA • v. 16 n. 1 • p. 79-100 • jun. 2013 
que, ao observar as áreas dessas comunidades, as políticas públicas de concessão florestal estariam considerando não apenas os usos múltiplos dos recursos naturais por parte das mesmas, mas o próprio espaço de sobrevivência e de reprodução familiar.

Ademais, tal processo requer ainda a produção de relações sustentáveis entre os projetos de exploração florestal decorrentes das concessões florestais e as comunidades ribeirinhas do Mamuru-Arapiuns, tanto no que diz respeito ao recrutamento de mão-de-obra nas comunidades para as atividades dos empreendimentos madeireiros, quanto no que se refere ao uso de recursos naturais nas formas comerciais pelos comunitários, como a comercialização de produtos florestais não madeireiros, por exemplo. A ideia é que tal integração não crie processos incompatíveis com a gestão comunitária do processo produtivo, essencialidade à condição de processo sustentável.

\section{REFERÊNCIAS}

ALMEIDA, A.W.B. de. Terras de preto, terras de santo, terras de índio: uso comum e conflito. In: CASTRO, E.; HÉBETTE, J. (Org.). Na trilha dos Grandes Projetos: modernização e conflito na Amazônia. Belém: NAEA/ UFPA, 1989. p. 163-196.

BARBOSA, M.B.C.; MARIN, R.E.A. Manejo e uso comum dos recursos naturais em populações quilombolas no Vale do Rio Capim. Novos Cadernos NAEA, Belém, v. 13, n. 1, p. 27-45, 2010.

CASTRO, E. Território, Biodiversidade e Saberes de Populações Tradicionais. In: DIEGUES. A.C. (Org.). Etnoconservação: novos rumos para a conservação da natureza. 2. ed. São Paulo: Hucitec, 2004. p. 165-182.

COSTA, F. de A. Economia camponesa nas fronteiras do capitalismo: teoria e prática nos EUA e na Amazônia brasileira. Belém: NAEA, 2012.

Questão agrária e macropolíticas na Amazônia. Estudos Avançados, São Paulo, v. 19, n. 53, p. 131-156, 2005.

CUNHA, M.C. da; ALMEIDA, M.W.B. Populações tradicionais e conservação ambiental. In: CUNHA, M.C. da. Cultura com aspas e outros ensaios. São Paulo: Cosac Naify, 2009.

DIEGUES, A.C. As Populações Tradicionais: Conflitos e Ambiguidades. In: DIEGUES, A.C. O mito moderno da natureza intocada. 3. ed. São Paulo: Hucitec, 2001. p. 75-98. 
FOLADORI, G.; TAKS, J. Um olhar antropológico sobre a questão ambiental. Mana, Rio de Janeiro, v. 10, n. 2, p. 323-348, 2004.

FOSTER, J.B. A ecologia de Marx: materialismo e natureza. Rio de Janeiro: Civilização Brasileira, 2005.

HAWLEY, A. Human Ecology: a theoretical essay. Chicago: Chicago University Press, 1986.

IDEFLOR. Pesquisa Socioambiental na região Mamuru-Arapiuns, Pará. Belém, 2009 (Relatório Técnico).

KOENIG, Samuel. Elementos da Sociologia. Rio de Janeiro: Guanabara, 1988.

MAUÉS, R.H. Por que uma Agenda 21 para a Amazônia? In: ARAGÓN, L.E. (Org.). Debates sobre a Agenda Amazônia 21. Belém: UNAMAZ, 2000. p. $31-40$.

MORAES, R. Na planície amazônica. 7. ed. Belo Horizonte: Itatiaia, 1987.

PALHA, M. das D.C.; TOURINHO, M.M. Religiosidade e racionalismo ambiental no estuário do rio Amazonas. In: GAMA, J.R.V.; PALHA, M. das D.C.; SANTOS, S.R.M. dos (Org.). A natureza e os ribeirinhos. Belém: UFRA, 2009. p. 15-26.

PEREIRA, B.E.; DIEGUES, A.C. Conhecimento de populações tradicionais como possibilidade de conservação da natureza: uma reflexão sobre a perspectiva da etnoconservação. Desenvolvimento e Meio Ambiente, Curitiba, n. 22, p. 37-50, 2010.

PEREIRA, M.S.; WITKOSKI, A.C. Construção de paisagem, espaço e lugar na várzea do rio Solimões-Amazonas. Novos Cadernos NAEA, Belém, v. 15, n. 1, p. 273-290, 2012.

SAYAGO, D.A.V.; BURSZTYN, M. A tradição da ciência e a ciência da tradição: relações entre valor, conhecimento e ambiente. In: GARAY, I.; BECKER, B.K. (Org.). Dimensões humanas da biodiversidade: o desafio de novas relações sociedade-natureza no século XXI. Rio de Janeiro: Vozes, 2006. p. 89-110.

.; TOURRAND, J.-F; BURSZTYN, M. Um olhar sobre a Amazônia: das cenas aos cenários. In: SAYAGO, D.A.V.; TOURRAND, J.; BURSZTYN, M. (Org.). Amazônia: cenas e cenários. Brasília: Universidade de Brasília, 2004. p. $17-28$.

SCHUMACHER, E.F. O negócio é ser pequeno (small is beautiful): um estudo de economia que leva em conta as pessoas. Rio de Janeiro: Zahar, 1979. 
SHIVA, V. Monoculturas da mente: perspectivas da biodiversidade e da biotecnologia. São Paulo: Gaia, 2003.

TEISSERENC, P. Reconhecimento de saberes locais em contexto de ambientalização. Novos Cadernos NAEA, Belém, v. 13, n. 2, p. 5-26, 2010.

TOCANTINS, L. O rio comanda a vida: uma interpretação da Amazônia. 8. ed. Rio de Janeiro: Record, 1988.

TOURINHO, M.M. Manejo comunitário: complexidade além dos recursos (A Teoria Geral dos Sistemas (Bertalanffy, 1968) e a Teoria dos Sistemas Sociais (Parsons, 1951) como ferramentas para trabalhar o manejo comunitário dos recursos naturais). In: SEMINÁRIO ÁGUA E MEIO AMBIENTE NA AMAZÔNIA. 2007, Belém. Anais... Belém: MPEG, 2007.

WAGLEY, C. Uma comunidade amazônica: estudo do homem nos trópicos. São Paulo: Companhia Editora Nacional, 1957.

WALDMAN, M. Meio ambiente e antropologia. São Paulo: Senac, 2006.

WITKOSKI, A.C. Terras, florestas e águas de trabalho: os camponeses amazônicos e as formas de uso de seus recursos naturais. 2. ed. São Paulo: Annablume, 2010. 
